Bond University

Research Repository

\title{
The Safety and Tolerability of Statin Therapy in Primary Prevention in Older Adults: A Systematic Review and Meta-analysis
}

Zhou, Zhen; Albarqouni, Loai; Curtis, Andrea J; Breslin, Monique; Nelson, Mark

Published in:

Drugs and Aging

DOI:

10.1007/s40266-019-00736-y

Licence:

Other

Link to output in Bond University research repository.

Recommended citation(APA):

Zhou, Z., Albarqouni, L., Curtis, A. J., Breslin, M., \& Nelson, M. (2020). The Safety and Tolerability of Statin Therapy in Primary Prevention in Older Adults: A Systematic Review and Meta-analysis. Drugs and Aging, 37(3), 175-185. https://doi.org/10.1007/s40266-019-00736-y

\section{General rights}

Copyright and moral rights for the publications made accessible in the public portal are retained by the authors and/or other copyright owners and it is a condition of accessing publications that users recognise and abide by the legal requirements associated with these rights.

For more information, or if you believe that this document breaches copyright, please contact the Bond University research repository coordinator 
1 Article Title: The safety and tolerability of statin therapy in primary prevention in older adults: A systematic

2 review and meta-analysis

3 Running Title: The risk of statins in healthy elderly

4 Authors: Zhen Zhou, MD, ${ }^{\mathrm{a}}$ Loai Albarqouni, MD, ${ }^{\mathrm{b}}$ Andrea J Curtis, $\mathrm{PhD},{ }^{\mathrm{c}}$ Monique Breslin, PhD, ${ }^{\mathrm{a}}$ Mark Nelson, $5 \mathrm{PhD}^{\mathrm{a}}$

6 Authors' affiliations: ${ }^{a}$ Menzies Institute for Medical Research, University of Tasmania, Hobart, Tasmania,

7 Australia; ${ }^{b}$ The Centre for Research in Evidence-Based Practice (CREBP), Faculty of Health Sciences and

8 Medicine, Bond University, Gold Coast, Queensland, Australia; ${ }^{\mathrm{c}}$ Department of Epidemiology and Preventive

9 Medicine, School of Public Health and Preventive Medicine, Monash University, Melbourne, Victoria, Australia.

10 Corresponding author: Zhen Zhou

\section{Corresponding author contact information:}

12 Email: zhen.zhou@utas.edu.au

13 Telephone: +610448160512

14

ORCID: 0000-0002-0835-8686 


\section{Abstract}

Introduction The use of statins for primary prevention of cardiovascular disease (CVD) is increasing in older adults. Nonetheless, good clinical evidence for the safety and tolerability of statins in this population is limited.

Objective We aimed to evaluate the safety and tolerability of statins in older adults without overt CVD, with focus on statin-related muscle symptoms.

Methods Double-blinded randomised controlled trials (RCTs) of statins published before January 2012 were identified from a Cochrane review updated to 2012. Trials published between January 2012 to July 2018 were identified through the CENTRAL, MEDLINE and EMBASE databases. Eligible trials were limited to those including individuals aged $\geq 65$ years without overt CVD, who were followed for at least one year. Trials should report at least one of the outcomes of interest. Pooled relative risk (RR) estimates and $95 \%$ confidence intervals (CIs) were calculated using the random-effects models.

Results Eleven trials including 18,192 participants were identified (mean age 73.7 years; $43 \%$ females). Compared with placebo, statins neither increase the risks of muscle-related symptoms (RR 1.01; 95\% CI 0.90 to 1.12), total adverse events (AEs) and serious AEs nor lead to more total permanent treatment discontinuations and discontinuations due to AEs or specifically due to muscle-related symptoms. No evidence of heterogeneity was observed in any of these outcomes.

Conclusions This meta-analysis of RCTs found no excess incidence of muscle-related symptoms, total AEs, serious AEs and treatment discontinuations attributable to statin compared with placebo among older adults without CVD.

Keywords Hydroxymethylglutaryl-CoA Reductase Inhibitors; Safety; Primary prevention; Aged; Meta-Analysis

\section{Key Points}

- The present meta-analysis of randomised controlled trials systematically evaluated the safety and tolerability of statins in older adults without overt cardiovascular disease (CVD).

- This meta-analysis found no significant difference in muscle-related symptoms, any adverse event and any serious adverse event between statin and placebo groups in older adults without CVD.

- This meta-analysis found no excess incidence of total treatment discontinuations and AE-related treatment discontinuations of statins relative to placebo in older adults without CVD. 


\section{Introduction}

46

Use of statins for the secondary prevention of cardiovascular disease (CVD) in older adults, defined as individuals aged 65 years and older, has been well-acknowledged and supported by a strong body of evidence [1]. However, for primary prevention with statins, recommendations in clinical guidelines from different countries are inconsistent in adults aged 65-75 years and are generally lacking in those aged 75 years and older, who have been largely underrepresented in clinical trials $[2,3]$. Despite this, there has been a marked increase of statin prescriptions for primary prevention in older adults over the past decade, owing to their higher disease burden and poorer outcomes following a first cardiovascular event [4-6]. The widespread use of statins in this subpopulation has raised great concerns about potential statin-related risks, upon which the clinical trial evidence is weak and limited [7].

Compared with younger adults, older adults seem to be more susceptible and less resilient to statin-related adverse events (AEs) and drug-drug interactions owing to decreased physiologic reserve, multiple morbidities and polypharmacy $[8,9]$. Statin-associated muscle symptoms (SAMS) are the most commonly reported AEs in clinical practice, occurring in approximately $7 \%$ to $29 \%$ of statin-users and contributing to up to $75 \%$ of treatment discontinuations of statins within two years of treatment initiation [10]. The clinical presentation of SAMS is highly heterogeneous, mainly characterised by muscle pain or aches (myalgia), muscle weakness, stiffness and cramp, with normal or slightly elevated creatine kinase (CK) concentrations [10]. For older adults, SAMS may substantially impact their independence and quality of life by exacerbating physical deconditioning and frailty [11]. Two rare and severe forms of SAMS - myopathy (defined as muscle symptoms with CK $>10 \times$ the upper limit of normal [ULN]) and rhabdomyolysis (defined as muscle symptoms with $\mathrm{CK}>40 \times \mathrm{ULN}$ when accompanied with renal impairment and/or myoglobinuria) are devastating and potentially life-threatening [10]. In real-world populations, it was estimated that the myopathy and rhabdomyolysis occur in 5 and 1.6 patients per 100,000 person-years, respectively [12].

The high incidence and prevalence of SAMS and other statin-related AEs were mainly observed in nonrandomised scenarios, including observational studies, patient registries and routine clinical settings [13]. However, owing to the lack of a comparator in these contexts, any relation between reported AEs and statin use can only be seen as associative. In contrast, results yielded using data from randomised controlled trials (RCTs) that enable the establishment of causal relations, should provide more reliable evidence of actual statin attributable 
AEs. Therefore, we conducted a systematic review and meta-analysis of RCTs to comprehensively evaluate the safety and tolerability of statins versus placebo in primary prevention in older adults, with a focus on the risk of SAMS. We also assessed the incidence of total AEs, serious AEs (SAEs), and permanent treatment discontinuations between statin and placebo groups, as these outcomes present the general safety and tolerability profiles of a treatment.

\section{Methods}

\subsection{Systematic Review Registration}

The study protocol has been previously registered (PROSPERO: CRD42017058436) and published [14]. This systematic review and meta-analysis was reported in accordance with the Preferred Reporting Items for Systematic Reviews and Meta-Analyses (PRISMA) method [15].

\subsection{Data Sources and Study Selection}

We selected eligible trials published before January 2012 from the reference lists of a published Cochrane systematic review (updated to 2012) of RCTs of statins including adults without established CVD [16]. A new search using the CENTRAL, MEDLINE and EMBASE databases was conducted to identify eligible trials published between January 2012 and July 2018. The full search strategy was outlined in our protocol [14]. No language restrictions were applied. We also manually searched relevant reviews and the reference lists of eligible articles to supplement the electronic search. Two reviewers (Z.Z., L.A.) screened the titles and abstracts of articles independently against the selection criteria. The full text of articles that potentially met the eligibility criteria were retrieved. Discrepancies were resolved by discussion with a third reviewer (M.N.).

\subsection{Selection Criteria}

We included studies that met the following criteria: 1) double-blind RCTs of statins versus placebo with at least one-year follow-up and; 2) reporting at least one outcome of interest (defined below in section 2.4 Outcomes) in (subgroup of) participants aged 65 years or more without overt CVD. 
We also excluded studies that 1) targeted participants with certain pre-existing conditions including cancer, hypothyroidism, acute infection, chronic kidney disease, human immunodeficiency virus infection, posttransplantation, or any other acute illness, which may increase the risk of AEs [17]; 2) studied cerivastatin, which was withdrawn from the market in 2001 or; 3) studied a combination of statins with any other lipid-lowering medication as the study treatment.

\subsection{Outcomes}

The primary outcome was adverse muscle symptoms including myalgia, muscle weakness, stiffness, tenderness and cramp (myopathy and rhabdomyolysis were not included) [10].

Other outcomes included myopathy, rhabdomyolysis, any AE (refers to the AEs recorded in the original trial; we did not exclude adverse muscle symptoms, myopathy and rhabdomyolysis if these outcomes were counted as AEs in the original trial), any SAE (defined as adverse experiences that were considered serious including lifethreatening, causing death or a permanent disability or incapacity, resulting in or prolonging hospitalisation) [18], permanent treatment discontinuation of statins or placebo due to any reason, AEs or adverse muscle symptoms.

\subsection{Data Extraction and Quality Assessment}

Two reviewers (Z.Z., L.A.) independently extracted data using a predefined, standardised data extraction sheet. When trial outcome data was published in a form that corresponded to our age eligibility criteria (age $\geq 65$ years) it was extracted directly from the publication in aggregate form. If there was no subgroup data provided for the over 65 age group, we requested individual patient data from the corresponding authors and/or pharmaceutical sponsors of the original trial and performed the appropriate analysis for that age group. The risk of bias of included trials was assessed using the Cochrane's Risk of Bias Tool (RevMan Version 5.3.5, The Cochrane Collaboration) [19]. We assessed the overall risk of bias for each trial based on the judgement of each domain as high, low or unclear risk and rated it by the highest risk assigned across individual domains. We used the Grading of Recommendations Assessment, Development, and Evaluation (GRADE) approach to rate the quality of evidence for each outcome across all the trials as very low, low, moderate or high, with a 'Summary of findings' table created [20]. More details can be found in our published protocol [14]. 


\subsection{Data Synthesis and Analysis}

128 To account for a between-study variation in the effect sizes of an outcome, we employed the DerSimonian and 129 Laird random-effects models to perform meta-analyses of outcomes (except for myopathy and rhabdomyolysis)

130 [21]. Results of the analyses were presented as risk ratios (RRs) with 95\% confidence intervals (95\% CIs). We provided a narrative statement for myopathy and rhabdomyolysis as most included trials reported zero events of these two outcomes in both arms.

Between-study heterogeneity was assessed using the $\mathrm{I}^{2}$ statistic [22]. $\mathrm{I}^{2}$ values of $0 \%-40 \%, 30 \%-60 \%, 50 \%$ $90 \%$, and $75 \%-100 \%$ correspond to negligible, moderate, substantial and considerable heterogeneity, respectively [21]. Subgroup analyses were conducted for the primary outcome based on pre-specified factors including followup duration ( <3-year, $\geq 3$-year), the dose intensity of statins (standard, intensive, multiple) [23], and the solubility of statins (hydrophilic, lipophilic). As only nine trials reported the primary outcome, we were unable to assess publication bias using funnel plots and Egger's regression test as planned [24]. A leave-one-out sensitivity analysis was conducted by iteratively removing one study at a time to assess the impact of every single study. Metaregression was not conducted to minimise the risk of false positives [25]. considered statistically significant.

\section{Results}

\subsection{Trials Retrieved and Study Characteristics}

The trial selection flowchart is presented in Fig. 1. Of 9,751 citations identified initially by our new established search, 71 articles were retrieved for full review and two publications from one trial (Heart Outcomes Prevention Evaluation [HOPE] -3 trial [26]) met our eligibility criteria in the database search. However, this trial had a wider age-range criterion and was excluded later as separate data for older adults could not be obtained [27]. Ten RCTs selected from the Cochrane review and one from the manual search were included in the final analyses, with a total of 18,192 subjects included (mean age 73.7 years; $43 \%$ females; median follow-up 3.0 years).

Fig. 1 Study selection process. HOPE-3 Heart Outcomes Prevention Evaluation-3, RCT randomised controlled trial. a: Trial by Bruckert et al. b: MRC/BHF (Medical Research Council/British Heart Foundation) Heart Protection study [28], HOPE-3 trial [26] and ACAPS (Asymptomatic Carotid Artery Plaque Study) trial [29]. 

the post-hoc analyses of the primary trials [32-34]. Data from 4 trials were extracted from individual patient data [35-38]. Data from the PROSPER trial [39] were obtained from the meta-analysis by Teng et al. [40] and data from the ASCAPS-TexCAPS trial [41] were from the meta-analysis by Iwere et al [42].

\subsection{Risk of Bias and Quality of Evidence}

Results of the risk of bias assessment are presented in Fig. 2. In terms of the rating of methodological quality items across all included trials, half of the trials were rated as having an unclear risk of bias for the random sequence generation and for the allocation concealment. Most of the trials were rated as having an unclear or high risk for the item of 'other bias' because they were funded by pharmaceutical companies. For the remaining items, the majority of included trials were rated as having a low risk of bias. In terms of the methodological quality for each individual trial, eight trials (ASCAPS-TexCAPS 1998 [41], PROSPER 2002 [39], CARDS 2004 [34], PREVEND IT 2004 [37], ASPEN 2006 [38], Bone 2007 [36], METEOR 2007 [35] and ASCOT-LLA 2011 [32, 43 ]) were rated as having an unclear risk of bias, and three trials (Chan 1996, [31] Bruckert 2003, [30] JUPITER 2010 $[33,44])$ were rated as having a high risk of bias.

Fig.2 Risk of bias' summary (a) and graph (b): review author's judgements about each methodological quality item presented as percentages across all included trials (a) and for each included trial (b) according to the GRADE approach (Supplementary Table. 1). The quality of evidence on adverse muscle symptoms, AEs, SAEs, permanent treatment discontinuations due to AEs and due to muscle-related symptoms was rated moderate and on myopathy, rhabdomyolysis and total permanent discontinuations was rated low. 
181 Nine trials with $7.7 \%(642 / 8346)$ of participants in the statin group versus $7.5 \%(622 / 8287)$ of participants in the 182 placebo group reported adverse muscle symptoms. There was no significant difference in the risk of adverse muscle symptoms between the two groups (RR 1.01, 95\% CI 0.90 to $1.12, p=0.50, \mathrm{I}^{2}=1.1 \%$ ) (Fig. 3).

Fig. 3 Relative risks along with 95\% confidence intervals of adverse muscle symptoms between the statin and placebo groups. CI confidence interval.

\subsection{Myopathy and rhabdomyolysis}

Seven trials with $0.06 \%(4 / 6724)$ of participants treated with statins versus $0.05 \%(3 / 6655)$ treated with placebo reported myopathy. Of seven trials with available data on rhabdomyolysis, only one case $(1 / 7691)$ in the statin group and none $(0 / 7617)$ in the placebo group were recorded.

\subsection{AE and SAE}

Six trials with $34.3 \%(581 / 1694)$ of participants treated with statins versus $30.0 \%(468 / 1560)$ treated with placebo reported AEs. Seven trials with 28.0\% (2238/7989) of participants treated with statins versus 28.5\% (2270/7958) treated with placebo reported SAEs. The risks of both AEs (6 trials; RR 0.99, 95\% CI 0.95 to $1.04, p=0.95, \mathrm{I}^{2}=$ $0.0 \%$ ) and SAEs (RR $1.01,95 \%$ CI 0.97 to $1.05, p=0.89, \mathrm{I}^{2}=0.0 \%$ ) did not differ significantly between statin and placebo (Fig. 4).

\subsection{Permanent Treatment Discontinuation}

There were no significant differences observed in the incidence of total permanent treatment discontinuations (6 trials; RR 0.99, 95\% CI 0.81 to $\left.1.22, p=0.81, \mathrm{I}^{2}=0.0 \%\right)$, permanent treatment discontinuations due to AEs (8 trials; RR $1.05,95 \%$ CI 0.83 to $\left.1.33, p=0.59, \mathrm{I}^{2}=0.0 \%\right)$ and due to adverse muscle symptoms ( 6 trials; RR 1.17 , $95 \%$ CI 0.64 to $2.14, p=0.75, \mathrm{I}^{2}=0.0 \%$ ) of statins versus placebo (Fig. 4).

Fig. 4 Relative risks along with 95\% confidence intervals of adverse events, serious adverse events, total permanent discontinuations, discontinuations due to adverse events and adverse muscle symptoms. $A E$ adverse event, $C I$ confidence interval, $M S$ muscle-related symptoms. 


\subsection{Subgroup analyses}

209

The results of subgroup analyses suggest that our primary result was consistent regardless of the solubility and dosing of statins assigned and the length of follow-up duration of trials (Supplementary Fig. 1, 2, 3).

211

Supplementary Fig. 1 Subgroup analysis of adverse muscle symptoms in terms of the solubility of statins. $C I$ confidence interval

Supplementary Fig. 2 Subgroup analysis of adverse muscle symptoms in terms of the dose intensity of statins.

Supplementary Fig. 3 Subgroup analysis of adverse muscle symptoms in terms of the length of follow-up of trials. $C I$ confidence interval

\subsection{Sensitivity analysis}

The results yielded by the leave-one-out sensitivity analysis were consistent with the primary result, indicating that our primary finding was not driven by any single study (Supplementary Fig. 4).

Supplementary Fig. 4 Leave-one-out sensitivity analysis for the primary outcome. $R R$ relative risk, $C I$ confidence interval

\section{Discussion}

\subsection{Principal Findings}

In this meta-analysis of eleven RCTs, we found no evidence of an excess incidence of adverse muscle symptoms, AEs and SAEs attributable to statin compared to placebo in older adults without overt CVD. For myopathy and rhabdomyolysis, incidence rates were extremely low in both statin and placebo groups. Additionally, the incidence of total permanent discontinuations and of permanent discontinuations due to AEs or adverse muscle symptoms were not significantly different between statin and placebo groups. Our study findings supplement the current evidence base regarding the safety and tolerability of statin use in older adults in the primary prevention setting. 
We did not evaluate the risk of other purported statin-related AEs such as diabetes and haemorrhagic stroke, as they may only emerge after long-term statin exposure in large numbers of patients [45]. In a cohort study of 22,340 older adults, $45 \%$ discontinued statins within one year of treatment initiation [46]. It therefore seems likely that participants may be more concerned about the more immediate side effects of statins such as SAMS.

\subsection{Comparison with Other Studies and Possible Explanations}

Prior to our study, a meta-analysis by Teng et al [40] using published data from statin trials showed no increased risk of myalgias, SAEs and AE-related treatment discontinuations associated with statin use versus placebo/usual care in older adults without CVD. Our study updated their study findings by adding new data from four clinical trials, applying stringent selection criteria, and looking into additional safety-related outcomes which are clinically-relevant. Another meta-analysis of RCTs of older adults with and without CVD history by Iwere et al [42] also showed no significant difference in the risks of muscle-related symptoms and AE-related treatment discontinuations between statin and placebo/usual care groups.

Whilst our study findings were consistent with previous meta-analyses of RCTs, they do not concur with the high prevalence of SAMS and other statin-related AEs observed in routine clinical settings. In the absence of a comparator group in real-world scenarios, it is possible that patients and their health providers may misattribute symptoms to statins if that patient was currently taking statin drugs. Evidence for this is seen in a large cohort study in a routine care setting, in which more than $90 \%$ of statin-users who were re-challenged after suffering an AE could tolerate a statin long-term [47]. In fact, muscle complaints are frequently reported by older adults and the reasons can be diverse (i.e. sarcopenia, increased physical activity, diseases that lead to or increase the susceptibility to muscle problems, medications with known muscular toxicity) [10]. Such misattribution may prevent a substantial number of older adults from taking statins, and mean they forego potential cardiovascular benefits with more incident events as a consequence [10].

The "nocebo effect" may also provide some explanation for the higher prevalence of SAMS in real-world practice [48]. The 'nocebo effect' refers to the idea that subjective AEs such as aches and pain are due to patients' expectations of harm from statin therapy, because of their awareness and concerns about possible statin-related side effects [49]. In fact, the misattribution bias and 'nocebo effect' (if participants believe they are taking statins whether or not they are) may also occur in RCTs. Despite this, they impact statin and placebo groups equally. Hence their presence will not distort the estimates of treatment effects. In this meta-analysis, the incidence of 

adverse muscle symptoms was found to be similar between statin and placebo groups $(7.7 \%$ vs. $7.5 \%)$, further indicating that the AEs observed in the statin group were not necessarily related to the study treatment.

It is worth-noting that the generalisability of our study findings may be limited to routine clinical settings due to the inadequate representation of real-world populations. Participants within a clinical trial are more homogeneous than real-world populations, with regards to demographic, functional and clinical aspects. In this meta-analysis, most included trials involved predominantly white and older adults of age less than 80 years. Therefore, our study results may not apply to very old populations and other races or ethnicities. Trial participants also tend to be more motivated and to have better physical and psychological functioning, so that the risk of statinrelated AEs for these individuals is likely to be lower [50]. In view of this, evidence from clinical registries that reflect day-to-day clinical practice can be complementary to randomised evidence and provide some value for informing clinical decision-making, while also acknowledging the design limitations.

\subsection{Limitations}

Several limitations in this review need to be raised. Firstly, evidence quality of the outcomes in this review was rated from low to moderate. Therefore, the results should be interpreted with caution. Secondly, individual patient data from three identified trials $[26,28,29]$ could not be obtained, which lowers the study power. Thirdly, a median follow-up of 3 years of included trials may limit study ability to assess the safety and tolerability of statins over the long-term. However, common and immediate side effects of statins such as SAMS are more likely to be clinically-concerning issues that were reported to contribute to a high rate of statin discontinuations within the early period (1-2 years) of treatment initiation [10]. Fourthly, all the included trials were industry-sponsored and therefore may be biased in favour of the sponsor's drugs. However, this limitation is likely to be minimal as all the reported AEs were recorded by blinded personnel. Additionally, as seven included trials did not perform further subgroup analysis by age and participants' mean age in three trials was unknown, we were unable to conduct a subgroup analysis or meta-regression to assess whether age increases the risk of statin-related AEs and the incidence of treatment discontinuations of statins. Moreover, some trials have a small sample size and unbalanced treatment arms, which may influence the accuracy of the results. While no heterogeneity was observed in the meta-analyses of all outcomes, the small study effect appeared to be negligible. Finally, the study results may have generalisability considerations for patients in routine clinical settings. 


\section{Conclusions}

290

In this meta-analysis of RCTs, we found no evidence of an excess incidence of adverse muscle symptoms, total

291 AEs, SAEs and treatment discontinuations attributable to statin compared to placebo among older adults without

292 CVD. As statin intolerance and discontinuation remain important and unresolved clinical issues, further evidence 293 from high-quality RCTs that design priori to assess the safety and tolerability of statins in older adults without

294 CVD exclusively is warranted to provide more reliable evidence. 
313 Conflict of interests MN was on an Advisory Board for Amgen who make a lipid-lowering agent. ZZ, LA, AC and MB 314 declare that they have no conflict of interests. 
Table 1 Baseline characteristics and outcomes reported of the included trials

\begin{tabular}{|c|c|c|c|c|c|c|c|c|c|c|c|c|}
\hline Study name & Year & Country & $\begin{array}{c}\text { Patients (n) } \\
\text { (Statin } \\
\text { /placebo) }\end{array}$ & $\begin{array}{c}\text { Mean age } \\
\text { (Age range), } \\
\text { year }\end{array}$ & $\begin{array}{l}\text { Median } \\
\text { follow-up, } \\
\text { year }\end{array}$ & $\begin{array}{c}\text { Female } \\
(\%)\end{array}$ & $\begin{array}{l}\text { Statins } \\
(\mathrm{mg} / \mathrm{d})\end{array}$ & $\begin{array}{c}\text { Dosage } \\
\text { Intensity }\end{array}$ & $\begin{array}{l}\text { Baseline } \\
\text { LDL-C } \\
(\mathrm{mmol} / \mathrm{L})\end{array}$ & $\begin{array}{l}\text { run-in } \\
\text { (week) }\end{array}$ & $\begin{array}{l}\text { Stop } \\
\text { early }\end{array}$ & $\begin{array}{l}\text { Outcome } \\
\text { reported }\end{array}$ \\
\hline Chan et al[31] & 1996 & China & $\begin{array}{c}96 \\
(48 / 48)\end{array}$ & $77(\geq 65)$ & 1.0 & 51 & $\begin{array}{l}\text { Pravastatin }^{\mathrm{a}} \\
(15 \mathrm{mg} / \mathrm{d})\end{array}$ & Standard & 5.27 & $\begin{array}{c}\text { Dietary } \\
\text { (12) }\end{array}$ & No & $\begin{array}{l}\text { MS, AE, TPD, } \\
\text { PD-AE, PD-MS }\end{array}$ \\
\hline $\begin{array}{l}\text { ASCAPS- } \\
\text { TexCAPS[41] }\end{array}$ & 1998 & U.S. & $\begin{array}{c}1416 \\
(715 / 701)\end{array}$ & NR (65-75) & 5.2 & 25 & $\begin{array}{l}\text { Lovastatin }^{\mathrm{b}} \\
(20-40 \mathrm{mg} / \mathrm{d})\end{array}$ & Standard & 4.06 & $\begin{array}{c}\text { Dietary } \\
\text { (12) } \\
\text { Placebo } \\
\text { (2) }\end{array}$ & Yes & MY \\
\hline PROSPER[39] & 2002 & $\begin{array}{l}\text { Scotland, Ireland, } \\
\text { The Netherlands }\end{array}$ & $\begin{array}{c}3239 \\
(1585 / 1654)\end{array}$ & $75(70-82)$ & 3.3 & 59 & $\begin{array}{l}\text { Pravastatin }^{\mathrm{a}} \\
(40 \mathrm{mg} / \mathrm{d})\end{array}$ & Standard & 3.80 & $\begin{array}{l}\text { Placebo } \\
\text { (4) }\end{array}$ & No & $\begin{array}{c}\text { MS, MY, RB, } \\
\text { SAE }\end{array}$ \\
\hline $\begin{array}{l}\text { Bruckert et } \\
\text { al[30] }\end{array}$ & 2003 & $\begin{array}{c}\text { France, Italy, } \\
\text { Spain, Belgium, } \\
\text { Israel }\end{array}$ & $\begin{array}{c}1229 \\
(607 / 622)\end{array}$ & $76(69-92)$ & 1.0 & 75 & $\begin{array}{l}\text { Fluvastatin } \\
\qquad \mathrm{XL}^{\mathrm{b}} \\
(80 \mathrm{mg} / \mathrm{d})\end{array}$ & Standard & 5.18 & None & Yes & $\begin{array}{c}\text { MS, MY, AE, } \\
\text { SAE, TPD, PD- } \\
\text { AE, PD-MS }\end{array}$ \\
\hline $\begin{array}{l}\text { PREVEND } \\
\text { IT[37] }\end{array}$ & 2004 & The Netherlands & $\begin{array}{c}143 \\
(78 / 65)\end{array}$ & $70(65-76)$ & $\begin{array}{c}3.83 \\
\text { (mean) }\end{array}$ & 27 & $\begin{array}{l}\text { Pravastatin }^{\mathrm{a}} \\
(40 \mathrm{mg} / \mathrm{d})\end{array}$ & Standard & 4.30 & None & No & TPD, PD-AE \\
\hline CARDS[34] & 2004 & UK and Ireland & $\begin{array}{c}1129 \\
(572 / 557)\end{array}$ & $69(65-77)$ & 3.9 & 31 & $\begin{array}{l}\text { Atorvastatin }^{\mathrm{b}} \\
\qquad(10 \mathrm{mg} / \mathrm{d})\end{array}$ & Standard & 3.06 & $\begin{array}{l}\text { Placebo } \\
\text { (6) }\end{array}$ & Yes & $\begin{array}{c}\text { MS,MY,RB, AE, } \\
\text { SAE, PD-AE }\end{array}$ \\
\hline
\end{tabular}


This is a post-peer-review, pre-copyedit version of an article published in Drugs and Aging.

The final authenticated version is available online at: https://doi.org/10.1007/s40266-019-00736-y

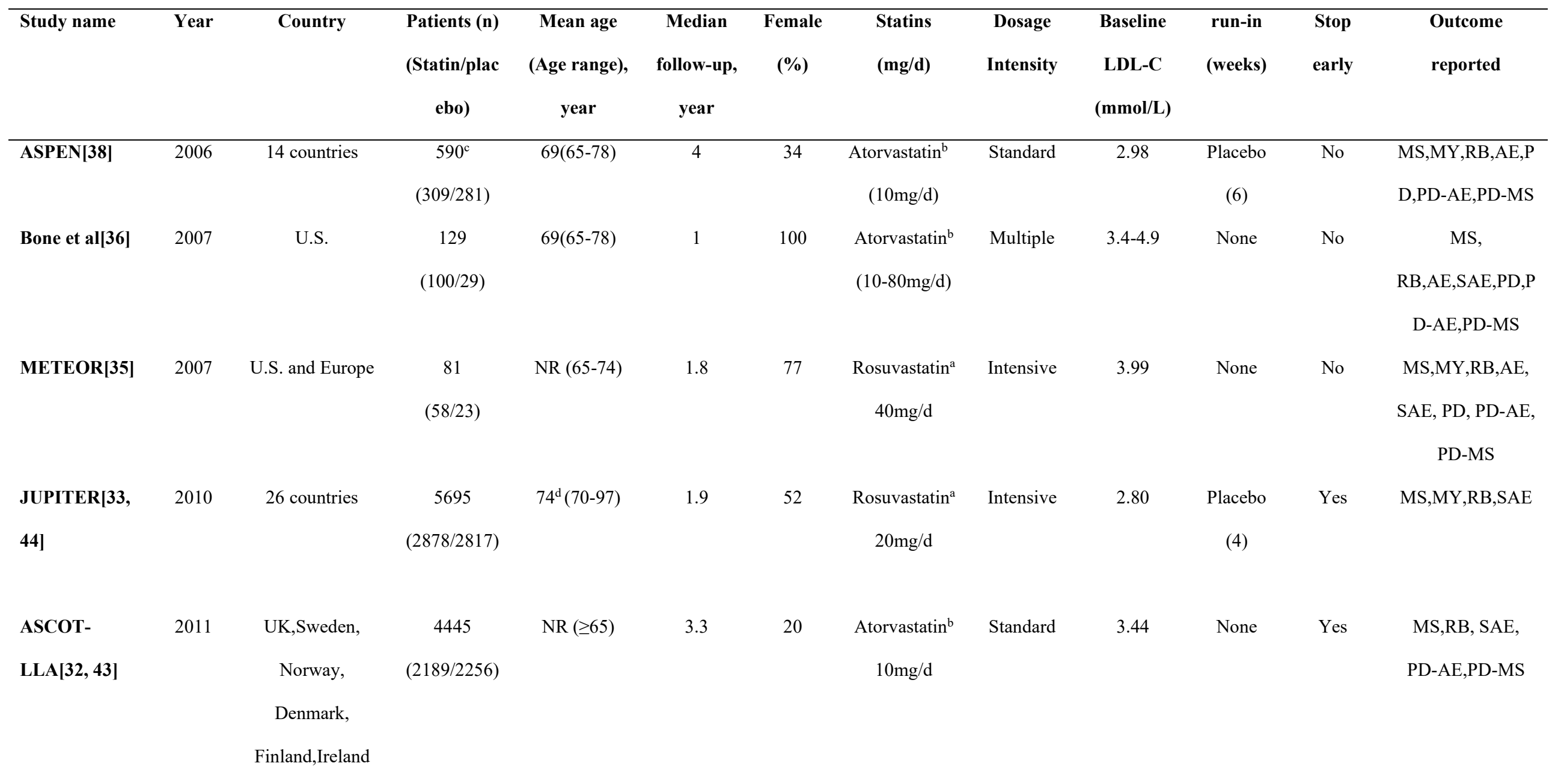

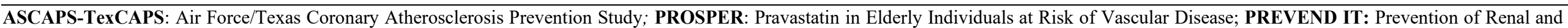

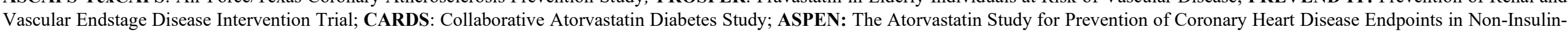

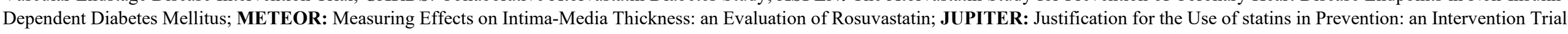

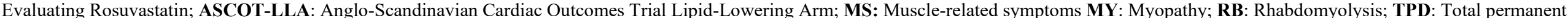

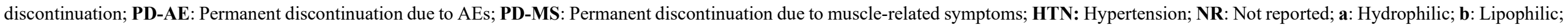
c: Patients with the history of angina were excluded; $\mathbf{d}$ : Median. 
This is a post-peer-review, pre-copyedit version of an article published in Drugs and Aging. The final authenticated version is available online at: https://doi.org/10.1007/s40266-019-00736-y

\section{References}

1. Grundy SM, Stone NJ, Bailey AL, Beam C, Birtcher KK, Blumenthal RS, et al. 2018 AHA/ACC/AACVPR/AAPA/ABC/ACPM/ADA/AGS/APhA/ASPC/NLA/PCNA Guideline on the Management of Blood Cholesterol: Executive Summary: A Report of the American College of Cardiology/American Heart Association Task Force on Clinical Practice Guidelines. J Am Coll Cardiol. 2019;73(24):3168-209.

2. Mortensen MB, Falk E. Primary Prevention With Statins in the Elderly. J Am Coll Cardiol. 2018;71(1):85-94.

3. Hawley CE, Roefaro J, Forman DE, Orkaby AR. Statins for Primary Prevention in Those Aged 70 Years and Older: A Critical Review of Recent Cholesterol Guidelines. Drugs Aging. 2019;36(8):68799.

4. Mortensen MB, Falk E, Schmidt M. Twenty-Year Nationwide Trends in Statin Utilization and Expenditure in Denmark. Circ Cardiovasc Qual Outcomes. 2017;10(7).

5. Ofori-Asenso R, llomaki J, Zomer E, Curtis AJ, Zoungas S, Liew D. A 10-Year Trend in Statin Use Among Older Adults in Australia: an Analysis Using National Pharmacy Claims Data. Cardiovasc Drugs Ther. 2018;32(3):265-72.

6. Salami JA, Warraich H, Valero-Elizondo J, Spatz ES, Desai NR, Rana JS, et al. National Trends in Statin Use and Expenditures in the US Adult Population From 2002 to 2013: Insights From the Medical Expenditure Panel Survey. JAMA Cardiol. 2017;2(1):56-65.

7. Gurwitz JH, Go AS, Fortmann SP. Statins for Primary Prevention in Older Adults: Uncertainty and the Need for More Evidence. JAMA. 2016;316(19):1971-2.

8. Golomb BA. Implications of statin adverse effects in the elderly. Expert Opin Drug Saf. 2005;4(3):389-97.

9. Bellosta $S$, Corsini A. Statin drug interactions and related adverse reactions: an update. Expert Opin Drug Saf. 2018;17(1):25-37.

10. Stroes ES, Thompson PD, Corsini A, Vladutiu GD, Raal FJ, Ray KK, et al. Statin-associated muscle symptoms: impact on statin therapy-European Atherosclerosis Society Consensus Panel Statement on Assessment, Aetiology and Management. Eur Heart J. 2015;36(17):1012-22.

11. Curfman G. Risks of Statin Therapy in Older Adults. JAMA Intern Med. 2017;177(7):966.

12. Valiyil R, Christopher-Stine L. Drug-related myopathies of which the clinician should be aware. Curr Rheumatol Rep. 2010;12(3):213-20.

13. Collins R, Reith C, Emberson J, Armitage J, Baigent C, Blackwell L, et al. Interpretation of the evidence for the efficacy and safety of statin therapy. Lancet. 2016;388(10059):2532-61.

14. Zhou Z, Albarqouni L, Breslin M, Curtis AJ, Nelson M. Statin-associated muscle symptoms (SAMS) in primary prevention for cardiovascular disease in older adults: a protocol for a systematic review and meta-analysis of randomised controlled trials. BMJ Open. 2017;7(9):e017587.

15. Liberati A, Altman DG, Tetzlaff J, Mulrow C, Gotzsche PC, loannidis JP, et al. The PRISMA statement for reporting systematic reviews and meta-analyses of studies that evaluate healthcare interventions: explanation and elaboration. BMJ. 2009;339:b2700.

16. Taylor F, Huffman MD, Macedo AF, Moore TH, Burke M, Davey Smith G, et al. Statins for the primary prevention of cardiovascular disease. Cochrane Database Syst Rev. 2013;(1):CD004816.

17. Grundy SM. Can statins cause chronic low-grade myopathy? Ann Intern Med.

2002;137(7):617-8.

18. Definitions

http://www.who.int/medicines/areas/quality safety/safety efficacy/trainingcourses/definitions.pdf . World Health Organisation. Access 15 Jan 2019.

19. Higgins J GS. Cochrane handbook for systematic reviews of interventions version 5.1.0. The Cochrane collaboration. 2011. 
20. Guyatt G, Oxman AD, Akl EA, Kunz R, Vist G, Brozek J, et al. GRADE guidelines: 1. Introduction-GRADE evidence profiles and summary of findings tables. J Clin Epidemiol. 2011;64(4):383-94.

21. Higgins J, Green S. Cochrane handbook for systematic reviews of interventions version 5.1.0. http://handbook-5-1.cochrane.org. The Cochrane collaboration. Access 15 Jan 2019.

22. Higgins JP, Thompson SG, Deeks JJ, Altman DG. Measuring inconsistency in meta-analyses. BMJ. 2003;327(7414):557-60.

23. Wang J, Chen D, Li DB, Yu X, Shi GB. Comparison of the efficacy and safety of intensive-dose and standard-dose statin treatment for stroke prevention: A meta-analysis. Medicine (Baltimore). 2016;95(39):e4950.

24. Egger M, Davey Smith G, Schneider M, Minder C. Bias in meta-analysis detected by a simple, graphical test. BMJ. 1997;315(7109):629-34.

25. Higgins JP, Thompson SG. Controlling the risk of spurious findings from meta-regression. Stat Med. 2004;23(11):1663-82.

26. Yusuf S, Bosch J, Dagenais G, Zhu J, Xavier D, Liu L, et al. Cholesterol Lowering in Intermediate-Risk Persons without Cardiovascular Disease. N Engl J Med. 2016;374(21):2021-31.

27. Yusuf S, Lonn E, Pais P, Bosch J, Lopez-Jaramillo P, Zhu J, et al. Blood-Pressure and Cholesterol Lowering in Persons without Cardiovascular Disease. N Engl J Med. 2016;374(21):203243.

28. Group MBHPSC, Armitage J, Bowman L, Collins R, Parish S, Tobert J. Effects of simvastatin 40 $\mathrm{mg}$ daily on muscle and liver adverse effects in a 5-year randomized placebo-controlled trial in 20,536 high-risk people. BMC Clin Pharmacol. 2009;9:6.

29. Furberg CD, Adams HP, Jr., Applegate WB, Byington RP, Espeland MA, Hartwell T, et al. Effect of lovastatin on early carotid atherosclerosis and cardiovascular events. Asymptomatic Carotid Artery Progression Study (ACAPS) Research Group. Circulation. 1994;90(4):1679-87.

30. Bruckert E, Lievre M, Giral P, Crepaldi G, Masana L, Vrolix M, et al. Short-term efficacy and safety of extended-release fluvastatin in a large cohort of elderly patients. Am J Geriatr Cardiol. 2003;12(4):225-31.

31. Chan P, Tomlinson B, Lee CB, Pan WH, Lee YS. Beneficial effects of pravastatin on fasting hyperinsulinemia in elderly hypertensive hypercholesterolemic subjects. Hypertension. 1996;28(4):647-51.

32. Collier DJ, Poulter NR, Dahlof B, Sever PS, Wedel H, Buch J, et al. Impact of atorvastatin among older and younger patients in the Anglo-Scandinavian Cardiac Outcomes Trial Lipid-Lowering Arm. J Hypertens. 2011;29(3):592-9.

33. Ridker PM, Danielson E, Fonseca FA, Genest J, Gotto AM, Jr., Kastelein JJ, et al. Rosuvastatin to prevent vascular events in men and women with elevated C-reactive protein. $\mathrm{N}$ Engl J Med. 2008;359(21):2195-207.

34. Colhoun HM, Betteridge DJ, Durrington PN, Hitman GA, Neil HA, Livingstone SJ, et al. Primary prevention of cardiovascular disease with atorvastatin in type 2 diabetes in the Collaborative Atorvastatin Diabetes Study (CARDS): multicentre randomised placebo-controlled trial. Lancet. 2004;364(9435):685-96.

35. Crouse JR, 3rd, Raichlen JS, Riley WA, Evans GW, Palmer MK, O'Leary DH, et al. Effect of rosuvastatin on progression of carotid intima-media thickness in low-risk individuals with subclinical atherosclerosis: the METEOR Trial. JAMA. 2007;297(12):1344-53.

36. Bone HG, Kiel DP, Lindsay RS, Lewiecki EM, Bolognese MA, Leary ET, et al. Effects of atorvastatin on bone in postmenopausal women with dyslipidemia: a double-blind, placebocontrolled, dose-ranging trial. J Clin Endocrinol Metab. 2007;92(12):4671-7.

37. Asselbergs FW, Diercks GF, Hillege HL, van Boven AJ, Janssen WM, Voors AA, et al. Effects of fosinopril and pravastatin on cardiovascular events in subjects with microalbuminuria. Circulation. 2004;110(18):2809-16. 
This is a post-peer-review, pre-copyedit version of an article published in Drugs and Aging. The final authenticated version is available online at: https://doi.org/10.1007/s40266-019-00736-y

38. Knopp RH, d'Emden M, Smilde JG, Pocock SJ. Efficacy and safety of atorvastatin in the prevention of cardiovascular end points in subjects with type 2 diabetes: the Atorvastatin Study for Prevention of Coronary Heart Disease Endpoints in non-insulin-dependent diabetes mellitus (ASPEN). Diabetes Care. 2006;29(7):1478-85.

39. Shepherd J, Blauw GJ, Murphy MB, Bollen EL, Buckley BM, Cobbe SM, et al. Pravastatin in elderly individuals at risk of vascular disease (PROSPER): a randomised controlled trial. Lancet. 2002;360(9346):1623-30.

40. Teng M, Lin L, Zhao YJ, Khoo AL, Davis BR, Yong QW, et al. Statins for Primary Prevention of Cardiovascular Disease in Elderly Patients: Systematic Review and Meta-Analysis. Drugs Aging. 2015;32(8):649-61.

41. Downs JR, Clearfield M, Weis S, Whitney E, Shapiro DR, Beere PA, et al. Primary prevention of acute coronary events with lovastatin in men and women with average cholesterol levels: results of AFCAPS/TexCAPS. Air Force/Texas Coronary Atherosclerosis Prevention Study. JAMA. 1998;279(20):1615-22.

42. Iwere RB, Hewitt J. Myopathy in older people receiving statin therapy: a systematic review and meta-analysis. Br J Clin Pharmacol. 2015;80(3):363-71.

43. Sever PS, Dahlof B, Poulter NR, Wedel H, Beevers G, Caulfield M, et al. Prevention of coronary and stroke events with atorvastatin in hypertensive patients who have average or lowerthan-average cholesterol concentrations, in the Anglo-Scandinavian Cardiac Outcomes Trial--Lipid Lowering Arm (ASCOT-LLA): a multicentre randomised controlled trial. Lancet. 2003;361(9364):114958.

44. Glynn RJ, Koenig W, Nordestgaard BG, Shepherd J, Ridker PM. Rosuvastatin for primary prevention in older persons with elevated C-reactive protein and low to average low-density lipoprotein cholesterol levels: exploratory analysis of a randomized trial. Ann Intern Med. 2010;152(8):488-96, W174.

45. Thompson PD, Panza G, Zaleski A, Taylor B. Statin-Associated Side Effects. J Am Coll Cardiol. 2016;67(20):2395-410.

46. Ofori-Asenso R, llomaki J, Tacey M, Si S, Curtis AJ, Zomer E, et al. Predictors of first-year nonadherence and discontinuation of statins among older adults: a retrospective cohort study. $\mathrm{Br} \mathrm{J}$ Clin Pharmacol. 2019;85(1):227-35.

47. Zhang H, Plutzky J, Skentzos S, Morrison F, Mar P, Shubina M, et al. Discontinuation of statins in routine care settings: a cohort study. Ann Intern Med. 2013;158(7):526-34.

48. Gupta A, Thompson D, Whitehouse A, Collier T, Dahlof B, Poulter N, et al. Adverse events associated with unblinded, but not with blinded, statin therapy in the Anglo-Scandinavian Cardiac Outcomes Trial-Lipid-Lowering Arm (ASCOT-LLA): a randomised double-blind placebo-controlled trial and its non-randomised non-blind extension phase. Lancet. 2017;389(10088):2473-81.

49. Barsky AJ, Saintfort R, Rogers MP, Borus JF. Nonspecific medication side effects and the nocebo phenomenon. JAMA. 2002;287(5):622-7.

50. Bitzur R, Cohen H, Kamari Y, Harats D. Intolerance to statins: mechanisms and management. Diabetes Care. 2013;36 Suppl 2:S325-30. 